\title{
PENGAPLIKASIAN RADIASI ELEKTROMAGNETIK TERHADAP PERTUMBUHAN VEGETATIF TANAMAN CABAI MERAH (Capsicum annum L.)
}

\author{
Bagus Santoso ${ }^{1}$, Amarullah Amarullah ${ }^{2}$, Dwi Santoso ${ }^{3 *}$ \\ 1,2,3 Program Studi Agroteknologi, Fakultas Pertanian Universitas Borneo Tarakan. \\ Jl. Amal Lama No.1, Kota Tarakan, Kalimantan Utara, Indonesia \\ *Email: dwiborneo11@gmail.com
}

Received : 13 Maret $2019 \quad$ Accepted : 5 April 2019

\begin{abstract}
Chili Plants (Capsicum annum L.) originating from the tropics and subtropicsAmericas, especially Colombia, South America, and continue to spread to Latin America. Evidence of chili cultivation was first discovered in Peru's historical siteand leftover seeds that are more than 5000 years old BC in a cave in Tehuacan, Mexico. The spread of chili to the whole world including countries in Asia, like Indonesia carried out by Spanish and Portuguese traders. The purpose of this study was to determine the effect of electromagnetic radiation on the growth and yield of red chilies in the city of Tarakan. This research was conducted from September 2018 to January 2019, at the screen house of the Faculty of Agriculture, Borneo Tarakan University. This study was prepared using factorial Randomized Block Design (RBD) with 5 treatments repeated 5 times. The factors studied were large electromagnetic radiation 56 microtesla with exposure time (P0) 0 minutes, (P1) 20 minutes, (P2) 40 minutes, (P3) 60 minutes, (P4) 80 minutes. Observation parameters; plant height, number of leaves, leaf length, leaf width, stem diameter and number of branches. Analysis of variance using variance ANOVA with a confidence level of $95 \%$ and if it is significantly different it will be continued with DMRT further testing. The results of the study show that: 1) Observation parameters that showed statistically significant differences were parameters of plant height, number of branches and number of leaves while parameters that did not show different results were parameters of leaf length, leaf width and stem diameter., 2) The best treatment for each observation parameter is P2 treatment (exposure to electromagnetic radiation for 40 minutes), and the lowest treatment is treatment P0 (without exposure to electromagnetic radiation). Suggestions from this study should be carried out further research on the use of electromagnetic radiation in the vegetative phase until the results of red chili plants (Capsicum annum L.)
\end{abstract}

Keywords: chili, electromagnetics radiation, Randomized Block Design

\begin{abstract}
ABSTRAK
Tanaman cabai (Capsicum annum L.) berasal dari dunia tropika dan subtropika Benua Amerika, khususnya Colombia, Amerika Selatan, dan terus menyebar ke Amerika Latin. Bukti budidaya cabai pertama kali ditemukan dalam tapak galian sejarah Peru dan sisaan biji yang telah berumur lebih dari 5000 tahun SM di dalam gua di Tehuacan, Meksiko. Penyebaran cabai ke seluruh dunia termasuk negara-negara di Asia, seperti Indonesia dilakukan oleh pedagang Spanyol dan Portugis. Tujuan dari penelitian ini adalah untuk mengetahui pengaruh radiasi elektromagnetik terhadap pertumbuhan dan hasil tanaman cabai merah di kota Tarakan. Penelitian ini dilaksanakan pada tahun 2018, di screen house Fakultas Pertanian Universitas Borneo Tarakan. Penelitian ini disusun dengan menggunakan Rancangan Acak Kelompok (RAK) faktorial dengan 5 perlakuan diulang sebanyak 5 kali. Faktor yang diteliti yaitu besar radiasi elektromagnetik 56 mikrotesla dengan lama pemaparan (P0) 0 menit, (P1) 20 menit, (P2) 40 menit, (P3) 60 menit, (P4) 80 menit. Parameter pengamatan; tinggi tanaman, jumlah daun, panjang daun, lebar daun, diameter batang dan jumlah cabang. Analisis ragam menggunakan sidik ragam Anova dengan tingkat kepercayaan 95\% dan apabila berbeda nyata maka akan dilanjut dengan uji lanjut DMRT. Hasil penelitian menunjukkan bahwa: 1) Parameter pengamatan yang menunjukkan hasil berbeda nyata secara statistik adalah parameter tinggi tanaman, jumlah cabang dan jumlah daun sedangkan parameter yang tidak menunjukkan hasil yang berbeda nayata adalah parameter panjang daun, lebar daun dan diameter batang, 2) Perlakuan terbaik untuk setiap parameter pengamatan adalah perlakuan P2 (pemaparan radiasi elektromagnetik selama 40 menit), dan perlakuan terendah adalah perlakuan P0 (tanpa pemaparan radiasi elektromagnetik). Saran dari penelitian ini sebaiknya dilakukan penelitian lanjutan mengenai penggunaan radiasi elektromagnetik pada fase vegetatif sampai hasil tanaman cabai merah (Capsicum annum $\mathrm{L}$.)

Kata kunci : cabai merah, radiasi elektromagnetik, Rancangan Acak Kelompok
\end{abstract}




\section{PENDAHULUAN}

Tanaman cabai (Capsicum annum L.) berasal dari dunia tropika dan subtropika Benua Amerika, khususnya Colombia, Amerika Selatan, dan terus menyebar ke Amerika Latin. Bukti budidaya cabai pertama kali ditemukan dalam tapak galian sejarah Peru dan sisaan biji yang telah berumur lebih dari 5000 SM di dalam gua di Tehuacan, Meksiko. Penyebaran cabai ke seluruh dunia termasuk negara-negara di Asia, seperti Indonesia dilakukan oleh pedagang Spanyol dan Portugis (Dermawan 2010).

Cabai atau lombok termasuk dalam suku terongterongan (Solanaceae) dan merupakan tanaman yang mudah ditanam di dataran rendah ataupun di dataran tinggi. Tanaman cabai banyak mengandung vitamin A dan vitamin $\mathrm{C}$ serta mengandung minyak atsiri capsaicin, yang menyebabkan rasa pedas bila digunakan untuk rempah rempah (Harpenas 2010).

Pertumbuhan tanaman cabai dipengaruhi oleh beberapa faktor diantaranya varietas, kualitas benih, kualitas biji, kualitas tanah dan metode budidaya yang digunakan. Metode budidaya yang sering digunakan diantaranya adalah pengolahan lahan, pemupukan, pemangkasan dan radiasi elektromagnetik. Radiasi adalah pancaran energi melalui suatu materi atau ruang dalam bentuk panas, partikel, atau radiasi elektromagnetik dari sumber energi. Radiasi dapat menginduksi terjadinya mutasi karena sel yang teradiasi akan dibebani oleh tenaga kinetik yang tinggi, sehingga dapat mempengaruhi atau mengubah reaksi kimia sel tanaman yang pada akhirnya dapat menyebabkan terjadinya perubahan susunan kromosom tanaman (Batan 2008).

\section{METODE PENELITIAN \\ Tempat dan Waktu Penelitian}

Penelitian ini dilaksanakan di screenhouse Fakultas Pertanian, Universitas Borneo Tarakan, tahun 2018.

\section{Alat dan Bahan}

Dalam penelitian ini alat yang digunakan meliputi rangkaian induktor elektromagnetik, kardus, alumunium foil, polibag, gunting, lem tembak, meteran, lakban, tembaga ukuran 0,3 $\mathrm{mm}$. Sedangkan bahan yang digunakan adalah bibit tanaman cabai merah.

\section{Rancangan Percobaan}

Rancangan penelitian ini menggunakan Rancangan Acak Lengkap (RAL). Penelitian ini menggunakan media polibag, dimana penelitian ini terdiri atas 5 perlakuan dengan masingmasing 5 ulangan. Pada pelaksanaan tersebut alat yang telah dibuat diletakkan ditengah-tengah tanaman, dengan jarak alat dari tanaman tersebut kurang lebih $10 \mathrm{~cm}$, radiasi yang dihasilkan sebesar $56 \mu \mathrm{T}$. Adapun perlakuan dari penelitian ini adalah P0 : Kontrol, P1 : Pemaparan raiasi selama 20 menit, P2 : Pemaparan radiasi selama 40 menit, P3 : Pemaparan radiasi selama 60 menit dan P4 : Pemaparan radiasi selama 80 menit.

\section{Parameter Pengamatan}

Parameter pada penelitian ini meliputi tinggi tanaman (cm), jumlah daun (helai), panjang daun $(\mathrm{cm})$, lebar daun $(\mathrm{cm})$, diameter batang $(\mathrm{cm})$, dan jumlah cabang. Bila hasil menenujukkan berbeda nyata maka akan dilanjutkan dengan uji DMRT (Duncan Multiple Range Test).

\section{HASIL DAN PEMBAHASAN}

\section{Hasil}

Berdasarkan hasil data pengamatan yang dilakukan dengan analisis sidik ragam, menunjukan bahwa pemberian radiasi elektromagnetik terhadap pertumbuhan vegetatif tanaman cabai merah (capsicum annum L.) memberikan pengaruh yang nyata terhadap beberapa parameter diantaranya tinggi tanaman, jumlah daun, dan jumlah cabang. Walaupun secara statistik parameter panjang daun, lebar daun, dan diameter batang tidak memberikan pengaruh yang nyata terhadap pertumbuhan vegetatif tanaman cabai merah (capsicum annum L.), tetapi perlakuan P2 (pemaparan radiasi 40 menit) menunjukan hasil yang tertinggi di setiap parameter pengamatan 
Tabel 1. Rata-Rata Parameter Tinggi Tanaman Akibat Pengaplikasian Radiasi Elektromagnetik

\begin{tabular}{lccccccc}
\hline \multirow{2}{*}{ PERLAKUAN } & & \multicolumn{7}{c}{ TINGGI TANAMAN } \\
\cline { 6 - 9 } & $1 \mathrm{MST}$ & $2 \mathrm{MST}$ & $3 \mathrm{MST}$ & $4 \mathrm{MST}$ & $5 \mathrm{MST}$ & $6 \mathrm{MST}$ & $7 \mathrm{MST}$ \\
\hline P0 & $16,72 \mathrm{e}$ & $24,02 \mathrm{e}$ & $27,34 \mathrm{e}$ & $31,14 \mathrm{~d}$ & $32,86 \mathrm{~d}$ & 33,34 & $34,83 \mathrm{de}$ \\
P1 & $21,2 \mathrm{c}$ & $25,35 \mathrm{c}$ & $28,16 \mathrm{~d}$ & $30,64 \mathrm{e}$ & $30,90 \mathrm{e}$ & 34,97 & $34,58 \mathrm{e}$ \\
P2 & $22,24 \mathrm{~b}$ & $29,52 \mathrm{~b}$ & $39,42 \mathrm{a}$ & $41,46 \mathrm{a}$ & $44,66 \mathrm{a}$ & 45,26 & $46,84 \mathrm{a}$ \\
P3 & $20,96 \mathrm{~d}$ & $24,57 \mathrm{~cd}$ & $31,60 \mathrm{c}$ & $33,48 \mathrm{c}$ & $33,47 \mathrm{c}$ & 36,70 & $39,07 \mathrm{c}$ \\
P4 & $23,94 \mathrm{a}$ & $31,62 \mathrm{a}$ & $34,00 \mathrm{~b}$ & $37,67 \mathrm{~b}$ & $39,61 \mathrm{~b}$ & 41,07 & $42,98 \mathrm{~b}$ \\
\hline F Hitung & $4,9 *$ & $7,24^{*}$ & $3,93^{*}$ & $3,44^{*}$ & $6,72^{*}$ & 2,75 & $3,66^{*}$ \\
F Tabel 5\% & 3,2 & 3,20 & 3,20 & 3,20 & 3,20 & 3,20 & 3,20 \\
\hline KK & 5,89 & 5,38 & 9,73 & 9,55 & 8,16 & 10,59 & 9,83 \\
\hline SD & 0,68 & 0,7 & 1,38 & 1,41 & 1,23 & & 1,55 \\
\hline DMRT & 0,54 & 0,56 & 1,10 & 1,13 & 0,98 & & 1,24 \\
\hline
\end{tabular}

Keterangan : P0= Kontrol, P1= pemaparan 20 menit, $\mathrm{P} 2=$ pemaparan 40 menit, $\mathrm{P} 3$ = pemaparan 60 menit, $\mathrm{P} 4=$ pemaparan 80 menit. Angka yang diikuti setiap huruf yang berbeda menunjukkan hasil yang berbeda nyata.

Tabel 3. Rata-Rata Parameter Jumlah Cabang Akibat Pengaplikasian Radiasi Elektromagnetik PERLAKUAN JUMLAH CABANG

\begin{tabular}{lcccc} 
& 4 MST & 5 MST & 6 MST & 7 MST \\
\hline P0 & $3,66 \mathrm{~b}$ & $6,61 \mathrm{c}$ & 4,60 & $7,41 \mathrm{~d}$ \\
P1 & $3,10 \mathrm{~d}$ & $6,00 \mathrm{de}$ & 2,80 & $6,80 \mathrm{e}$ \\
P2 & $6,93 \mathrm{a}$ & $9,97 \mathrm{a}$ & 4,60 & $13,03 \mathrm{a}$ \\
P3 & $2,82 \mathrm{e}$ & $6,00 \mathrm{e}$ & 4,00 & $9,12 \mathrm{~b}$ \\
P4 & $3,61 \mathrm{bc}$ & $7,60 \mathrm{~b}$ & 5,40 & $8,80 \mathrm{c}$ \\
\hline F Hitung & $8,73^{*}$ & $8,40^{*}$ & 2,11 & $4,23^{*}$ \\
F Tabel 5\% & 3,20 & 3,20 & 3,20 & 3,20 \\
\hline KK & 6,27 & 4,77 & 7,19 & 8,80 \\
\hline SD & 0,31 & 0,32 & & 0,66 \\
\hline DMRT & 0,25 & 0,26 & & 0,53
\end{tabular}

Keterangan : P0= Kontrol, P1= pemaparan 20 menit, $\mathrm{P} 2=$ pemaparan 40 menit, $\mathrm{P} 3$ = pemaparan 60 menit, $\mathrm{P} 4=$ pemaparan 80 menit. Angka yang diikuti setiap huruf yang berbeda menunjukkan hasil yang berbeda nyata

\section{PEMBAHASAN}

\section{Parameter Tinggi Tanaman}

Hasil analisis sidik ragam parameter tinggi tanaman menunjukkan hasil yang berbeda nyata pada pengamatan $1,2,3,4,5$ dan 7 MST, sedangkan pengamatan pada 6 MST menunjukan hasil yang tidak berbeda nyata. Pada 1 MST perlakuan terbaik ditunjukkan oleh perlakuan $\mathrm{P} 4$ $(23,94)$ perlakuan tersebut berbeda nyata dengan perlakuan lainnya, pada 4 MST perlakuan tertinggi adalah P2 $(41,46)$ berbeda nyata dengan perlakuan lainnya, pada 5 dan 7 MST perlakuan tertinggi adalah perlakuan P2 $(44,66)(46,84)$ yang berbeda nyata dengan perlakuan lainnya. Pada 6 MST perlakuan terbaik adalah perlakuan P2 $(45,26)$ tidak berbeda nyata dengan perlakuan lainnya.

Hasil analisis sidik ragam yang dilanjut dengan uji DMRT dengan taraf kepercayaan 5\% menunjukkan bahwa parameter tinggi tanaman pada 1,2,4,5 dan 7 MST menunjukkan hasil yang berbeda nyata untuk setiap perlakuannya. Perlakuan terbaik ditunjukkan oleh perlakuan P2 (pengaplikasian selama 40 menit) hal ini dikarenakan pada perlakuan 40 menit memberikan dampak yang baik pada pertumbuhan tinggi tanaman cabai merah, dibandingkan kontrol. Setiap pemaparan yang diberikan terhadap tanaman cabai merah memberikan reaksi yang baik. Jika pemaparan diberikan dengan waktu 20 menit (pengaplikasian tercepat) akan menyebabkan tanaman tumbuh lambat karena pemaparan yang kurang lama. Jika pemaparan terlalu lama juga akan menyebabkan tanaman kurang baik (Wawrecki et al., 2007). Hal tersebut menunjukkan bahwa bila radiasi listriknya rendah akan mengganggu pola pembelahan sel di maristem akar tanaman dan bila radiasi listriknya 
tinggi juga akan merusak akar. Pemberian radiasi elektromagnetik yang tepat akan memberikan reaksi yang baik pada tanaman cabai, Hasil pengukuran tinggi tanaman diketahui perlakuan terbaik adalah perlakuan P2 (pemaparan selama 40 menit), hal ini dikarenakan reaksi radiasi elektromagnetik pada tanaman cabai membuat sistem metabolisme cabai merah berjalan dengan baik. Interaksi radiasi elektomagnetik luar dengan partikel muatan listrik pada tanaman dapat mengakibatkan terserapnya energi radiasi elektromagnetik dan diubah ke dalam bentuk senyawa kimia sehingga dapat mempercepat proses fotosintesis (Aladjadjiyan., 2007).

\section{Parameter Jumlah Daun}

Hasil analisis sidik ragam parameter jumlah daun menunjukkan hasil yang berbeda nyata pada pengamatan 1,4 dan 5 MST, sedangkan 2,3,6 dan 7 MST menunjukkan hasil yang tidak berbeda nyata. Pada 1 MST perlakuan tertinggi terdapat pada perlakuan $\mathrm{P} 4(10,13)$ yang berbeda nyata dengan perlakuan lainnya, pada 4 MST perlakuan terbaik adalah P2 $(25,84)$ berbeda nayata juga dengan perlakuan lainnya, minggu 5 MST P2 juga menunjukkan hasil tertinggi $(28,00)$ yang berbeda nyata dengan perlakuan lainnya. Pada 2,3,6 dan 7 MST menunjukan hasil yang tidak berbeda nyata.

Dari hasil analisis sidik ragam yang dilanjut dengan uji DMRT dengan taraf kepercayaan 5\% menunjukkan bahwa parameter tinggi tanaman pada 1,4 dan 5 MST menunjukkan hasil yang berbeda nyata untuk setiap perlakuannya. Perlakuan tertinggi ditunjukkan oleh perlakuan P2 (pengaplikasian radiasi elektromagnetik selama 40 menit) berbeda nayata terhadap perlakuan lainnya. Hal ini diakibatkan karna pemberian pemaparan radiasi elektromanetik yang tepat akan menyababkan pertumbuhan dan perkembangan tanaman cabai merah lebih cepat. Menurut Galland (2005), dalam radiasi magnet statis terdapat ion yang dapat memacu peningkatan hormon pertumbuhan tanaman

Terutama hormon antokalin dan filokalin. Hormon antokalin merupakan hormon yang merangsang pembentukkan bunga, sedangkan hormon filokalin berfungsi sebagai perangsang pembentukan daun. Hal ini menunjukkan bahwa pemaparan radiasi elektromagnetik meningkatkan hormon filokalin sehingga memacu pertumbuhan jumlah daun. Jika pengaplikasian radiasi elektromagnetik semakin lama diberikan terhadap tanaman cabai merah akan menyebabkan pertumbuhan tanaman cabai merah mengalami pertumbuhan dan pertambahan jumlah daun yang lambat (Stenz et al., 1993) bahwa semakin tinggi sebuah radiasi listrik DC maka sifat merusak radiasi listrik mempunyai pengaruh negatif terhadap pertumbuhan tanaman yang berefek pada perubahan pola transport ion aktif dan pasif. Sehingga hasil fotosintesis yang akan diangkat atau dilarikan ke daun akan terhambat menyebabkan pertambahan jumlah daun menjadi sedikit.

\section{Parameter Jumlah Cabang}

Hasil analisis sidik ragam parameter jumlah daun menunjukkan hasil yang berbeda nyata pada pengamatan 4,5 dan 7 MST, sedangkan pada 6 MST tidak menunjukkan hasil yang berbeda nyata. Pada 4 MST perlakuan tertinggi adalah perlakuan P2 $(6,93)$ berbeda terhadap perlakuan lainnya, pada 5 MST perlakuan tertinggi adalah perlakuan P2 $(9,97)$ berbeda nyata dengan perlakuan lainnya dan pada 7 MST perlakuan tertinggi adalah perlakuan P2 (13,03). Secara statistik pengamatan pada 6 MST tidak berbeda nyata namun perlakuan tertinggi adalah perlakuan P4 $(5,40)$. Hasil uji DMRT menunjukkan bahwa radiasi elektromagnetik secara umum memberikan pengaruh yang berbeda nyata secara statistik pada umur tanaman pada umur 4,5 dan 7 MST terhadap pemaparan radiasi elektromagnetik yang diaplikasikan selama 4 minggu. Pemaparan radiasi elektromagnetik terbaik ditunjukkan oleh perlakuan P2 (pemaparan selama 40 menit) dengan rata-rata hasil tertinggi. Hal ini disebabkan oleh karena perlakuan P2 adalah perlakuan dengan pemaparan yang tepat, tidak terlalu lama dan juga tidak terlalu cepat, (Wawrecki et al., 2007), menunjukkan bahwa bila radiasi listriknya rendah akan mengganggu pola pembelahan sel di maristem tanaman dan bila radiasi listriknya tinggi juga akan merusak tanaman tersebut.

Sehingga saat pemaparan diberikan dengan waktu yang tepat akan memacu tanaman cabai merah untuk melakukan polarisasi sel-sel pada tanaman sehingga mempercepat sistem metabolisme dan akhirnya tanaman cabai merah dapat memperbanyak jumlah cabang hal ini dikarenakan karena adanya interaksi antara radiasi elektromagnetik terhadap tanaman cabai merah sesuai dengan pernyataan bahwa Interaksi radiasi elektomagnetik luar dengan partikel muatan listrik pada tanaman dapat mengakibatkan terserapnya energi radiasi elektromagnetik dan diubah kedalam bentuk 
senyawa kimia sehingga dapat mempercepat proses fotosintesis (Aladjadjiyan., 2007).

\section{KESIMPULAN}

Berdasarkan hasil penelitian ini dapat disimpulkan, pemaparan radiasi elektromagnetik selama 40 menit (perlakuan P2) dapat memberikan efek terbaik pada tanaman cabai. Hal tersebut terlihat pada meningkatnya nilai parameter tinggi tanaman, jumlah daun dan jumlah cabang

\section{DAFTAR PUSTAKA}

Agustina, R. 2008 Fisiologi dan Anatomi Cocor Bebek (Kalanchoe Pinnata Pers.) Yang ditumbuhkan dibawah pengaruh medan magnet. Seminar Nasional sains dan Teknologi-II. Universitas Bandar Lampung.

Aladjadjiyan A. 2007.The Use of Physical Methods for Plant Growing Stimulation in Bulgaria.Journal of Central European Agriculture. Vol 8 (2007) Pp. 369-373.

Anies. 2006. SUTET, Potensi Gangguan Kesehatan Akibat Radiasi Elektromagnetik SUTET. Jakarta: PT. Elex Media Komputindo.

Baafi . U.S. 2004. Sistem Tenaga Listrik: Polusi dan Pengaruh Radiasi Elektromagnetik Terhadap Kesehatan Masyarakat.

Batan (Badan Tenaga Nuklir Nasional). 2008. Dasardasar Fisika Radiasi. Jakarta (ID): Pusat Pendidikan dan Pelatihan Badan Tenaga Nuklir Nasional.

Galland, P. A. 2005.Magneto reception in Plant. Journal of Plant Research. The Botanical Society of Japan and Springer Verlag Tokyo 2005. 118 371-389.

Harpenas, Asep \& R. Dermawan. 2010. Budidaya Cabai Unggul. Penebar Swadaya. Jakarta. Kiatgamjorn P., Khan-ngern, W., dan Nitta, S. 2002. The Effect of Electric Field on Bean Sprout

Growing. ICEMC Bangkok. Institute of Technology Ladkrabang Bangkok.

Nimmi, V. dan Madhu, G. 2009. Effect Of Pre-sowing Treatment With Permanent Magnetik Field On. Rukmana, R., Y.Y. Oesman. 2006. Bertanam cabai dalam pot. Kanisius, Yogyakarta.

Saragih, H., Tobing, J. ,dan Silaban, O. 2010. Meningkatkan Laju Pertumbuhan Kecambah Kedelai Dengan Berbantuan Medan Magnetik Statik. Prosiding Seminar Nasional Fisika. Universitas Advent Indonesia. Bandung.

Stenz Weisenseel. 1993. Electrotropism of Maize (Zea mays L.) Roots Facts and Artifacts. Plant Physiol.101: 1107-1111.

Supiyanto. 2002. Fisika SMA. Jakarta: Erlangga.

Sunaryono, H., dan Rismunandar. 1984. Kunci Bercocok Tanam Sayur-sayuran Penting Di Indonesia. CV. Sinar Baru. Bandung.
Tjahjadi, N. 1991. Bertanam Cabai. Kanisius. Yogyakarta.

Wawrecki W., Zagorska-Marek, B. 2007.Influence of a Weak DC Electric on Root Meristem Architecture.Annals of Botany.100: 791-796. 